Lima: UNMSM, SEPS, ONPE. 2005, 408 pages

\title{
Gabriella Chiaramonti. Ciudadanía y representación en el Perú (1808-1860). Los itinerarios de la soberanía
}

\section{Alex Loayza}

\section{OpenEdition}

Journals

\section{Edición electrónica}

URL: http://journals.openedition.org/bifea/5034

DOI: $10.4000 /$ bifea. 5034

ISSN: 2076-5827

\section{Editor}

Institut Français d'Études Andines

Edición impresa

Fecha de publicación: 1 diciembre 2005

Paginación: 477-480

ISSN: 0303-7495

\section{Referencia electrónica}

Alex Loayza, « Gabriella Chiaramonti. Ciudadanía y representación en el Perú (1808-1860). Los itinerarios de la soberanía », Bulletin de l'Institut français d'études andines [En línea], 34 (3) | 2005, Publicado el 08 diciembre 2005, consultado el 03 diciembre 2020. URL : http://journals.openedition.org/bifea/5034 ; DOI : https://doi.org/10.4000/bifea.5034

\section{(c)}

Les contenus du Bulletin de l'Institut français d'études andines sont mis à disposition selon les termes de la licence Creative Commons Attribution - Pas d'Utilisation Commerciale - Pas de Modification 4.0 International. 
CHIARAMONTI, Gabriella. Ciudadanía y representación en el Perú (1808-1860). Los itinerarios de la soberanía. UNMSM/SEPS/ONPE. Lima, 2005, 408 p.

Gabriella Chiaramonti, una de las pioneras en la historia electoral en el Perú, nos presenta la primera parte de una amplia investigación publicada originalmente en italiano en el 2002. El objetivo de este libro es analizar, a través del sufragio, cómo se define y construye históricamente la ciudadanía y la representación en el Perú entre 1808 y 1860. Este marco temporal se justifica porque la crisis de la monarquía hispana producida por la abdicación de Fernando VII y la posterior promulgación de la constitución de Cádiz generó procesos electorales que proporcionaron una inesperada autonomía política a los poderes locales; hecho que según Chiaramonti marcó el proceso político republicano hasta 1860, cuando esta autonomía se va perdiendo por la intromisión del Estado y la aparición de organizaciones políticas.

Para sustentar esta tesis general, el libro se divide en tres capítulos. El primero «El Perú en la crisis del Imperio», presenta cómo en la segunda mitad del siglo XVIII en el virreinato peruano los objetivos políticos centralizadores de las reformas borbónicas se frustraron debido a que las intendencias no se consolidaron y más bien se reforzaron los poderes locales a través del restablecimiento de los cabildos españoles e indígenas. Esto significó que si por un lado, los peninsulares ocuparon gran parte de los puestos administrativos del Estado, por otro lado, el control del territorio quedó en manos de los criollos. Este hecho va a producir un ambiente político tenso que se agudizará tras la abdicación de Bayona. En tal sentido, en España y América (basados en una concepción antigua de la Monarquía) se reivindicó en el pueblo el derecho de ejercer la soberanía. Posteriormente, estas ideas tendrían presencia en la ambigua constitución 
de Cádiz que si bien suprimía las diferencias entre españoles y criollos así como la república de indios, asoció la definición de ciudadanía a la noción tradicional de vecino, hecho que se reforzaba al mantener a la parroquia como punto de partida del proceso electoral. Por ello, según la autora

«La ciudadanía y la representación no poseían unos fundamentos individuales sino comunitarios [...] En Cádiz, a la soberanía controlada desde el centro se contrapone una construcción de la representación de distinto origen: no era el Estado el que construía la ciudadanía sino la comunidad local». (p. 107)

Así, esta constitución, permitía una amplia intervención de la sociedad civil en la construcción de la ciudadanía y en la consolidación de una idea tradicional de representación (el mandato imperativo). En la práctica, esto minó el orden virreinal, porque la elección de nuevas municipalidades - con solo facultades administrativas - en un contexto político convulso hizo que cobraran importancia política, llegando a considerarse depositarios de la soberanía, lo cual ocasionó no solo conflictos con el Virrey sino también con otros núcleos urbanos de mayor jerarquía.

Los problemas anteriormente mencionados son analizados más detenidamente en el segundo capítulo «La constitución de Cádiz desembarca en Lima». Al respecto, Chiaramonti menciona que el virrey Fernando Abascal era consciente de los inconvenientes de la constitución de Cádiz para mantener el orden y la unidad del virreinato. Así, la abolición del tributo le dejaba sin recursos para mantener la milicia y por otra parte la libertad de prensa difundía ideas subversivas. Pese a ello, Abascal acató e hizo juramentar la constitución y convocó a elecciones porque sabía que era el único medio de legitimar su gobierno. Sobre la juramentación, Chiaramonti resalta las características barrocas y religiosas de la ceremonia porque ello confirmaría simbólicamente el retorno a la tradición pactista. Respecto a las elecciones para elegir diputados para las cortes y constituir los ayuntamientos constitucionales, se da cuenta de la amplia participación electoral de todos los sectores de la población, incluyendo la población indígena (a la cual se da mayor atención para desvirtuar las afirmaciones que señalan su ausencia o pasividad en las elecciones). Este hecho se debía a las características del sistema electoral indirecto de cuatro grados y de dos grados (para elegir diputados y constituir ayuntamientos, respectivamente) que permitía una amplia participación en los primeros grados para después ir cerrando las elecciones en un grupo más reducido. Según Chiaramonti esto produjo «una "oligarquización" de la representación y, por la otra, el reforzamiento del localismo en las primeras fases del proceso» (p. 143). Por otra parte, la novedad de las elecciones radicó en que se integró, aunque no sin conflictos, a la república de españoles y de indios permitiendo que en ellas salieran representantes de ambos grupos si contaban con mayoría, aunque también expresaron mutuos acuerdos. Por esto y para mantener el orden y evitar aspiraciones autonomistas, Abascal trató de manejar las elecciones de ayuntamientos para que salieran elegidos representantes de su confianza. Sin embargo, esto no fue del todo posible porque la definición de los requisitos para los ciudadanos-electores estaba en manos de las parroquias. Por ello, una vez elegidas, Abascal buscó resquicios legales para limitar sus funciones originando conflictos en Cusco, Puno, Arequipa y Lima. Así, pese a sus intentos, los ayuntamientos debilitaron el poder del Estado y rompieron con las jerarquías territoriales; hechos que no cambiaron en 1814 cuando se restablecieron los antiguos cabildos tras disolución de la constitución de Cádiz.

El tercer y último capítulo, «El legado de Cádiz (1821-1860)», busca comprender los fundamentos del nuevo sistema republicano: su idea de nación, ciudadanía y representación a través de un minucioso análisis de las constituciones, las leyes electorales y las prácticas políticas que produjeron. De esta manera, Chiaramonti desplaza el análisis de las acciones de los caudillos llamando la atención en la estabilidad institucional que existía en el parlamento (expresado en su producción legislativa y constitucional) y las municipales; hecho necesario para los caudillos ya que les permitía legitimar su poder a través del sufragio. Así, señala que en la dinámica política de la época interactuaban tres actores: los caudillos, el parlamento y las comunidades locales que elegían representantes y tenían la capacidad de aceptar o rechazar a los gobiernos de 
turno. En su análisis presenta cómo entre 1821 y 1860 persistieron las nociones de ciudadanía y representación constituidas tras los procesos electorales gaditanos. Así, sobre la ciudadanía, llama la atención sobre sus raíces municipales (dado su control del registro cívico para decidir quién votaba), hecho que explicaría que se le asignará la misma categoría de vecino. También menciona que en el Perú, a diferencia de otros países, existía un sufragio amplio que permitía el voto de los indígenas como una manera de integrarlos a la «nación cívica». Sin embargo, de este hecho no se deducía que la participación en todas las fases de la representación política era igualitaria. Todo lo contrario, existían mecanismos para seleccionar quiénes tenían derecho a elegir y ser elegidos: el sistema de elección de dos grados o indirecto (colegios parroquiales y provinciales) y los requisitos para ser elegido representante (vecindad). En tal sentido, se recalca que a diferencia de Francia la representación en el Perú no se construyó a partir de nuevas circunscripciones territoriales uniformes y definidas sino más bien sobre las coloniales: las intendencias, los partidos y las parroquias. Así, mientras el sufragio en la parroquia era amplio y daba legitimidad a las comunidades locales y a los ciudadanos, en el nivel provincial (en la elección de senadores y diputados) se representaba una nación como un conjunto de territorios y no de ciudadanos. Es decir, la nación descrita por los diputados americanos en las cortes. Por ello, las elecciones lejos de ser un acto por el cual la sociedad elige a sus representantes se convierte en un proceso de negociación entre diferentes grupos de notables y sus redes sociales. Estos hechos no cambiarán con la breve experiencia del sufragio directo entre 1855-1860. Al respecto, Chiaramonti llama la atención sobre la agudización del control local de las elecciones que hizo posible la elección de más de un representante, lo cual llevó a que en la constitución de 1860 se retornará al sufragio indirecto.

Como último punto, Chiaramonti analiza la relación entre los caudillos y los pueblos. Así, a través de la lectura de las constituciones repara en que a excepción de Cádiz y la carta de 1823, que sitúan la soberanía en la nación, no existe en las demás un artículo que señale claramente quién detentaba la soberanía. Esto le permite afirmar que estas fuentes muestran las ambigüedades de la naturaleza administrativa o representativa de las municipalidades, que se asumen como pueblos soberanos cuando consideraban roto el pacto social; es decir, veían su adhesión al Estado no como una integración conjunta sino como una asociación entre diferentes cuerpos soberanos. Así, siguiendo a Antonio Annino, se afirma que

«Los acuerdos con los pueblos precedían y preconstituían los acuerdos de las asambleas y fundaba la legitimidad de la acción del caudillo, que más que una revuelta militar aparecía como un movimiento municipalista encabezado por un jefe militar». (p. 332)

Esto cambió en el periodo de 1855 y 1862 debido a que con el crecimiento de la burocracia local se inicia un proceso de legitimación entre el centro y las periferias políticas que se expresó en la creación de nuevas provincias y el aumento del número de representantes parlamentarios. Finalmente, el libro concluye señalando que el problema de la gobernabilidad durante la primera mitad del siglo XIX radicó, por un lado, en la carencia de un centro político y de una elite dirigente $y$, por otro lado, en la existencia de una fuerte «sociedad de sociedades» conformada por «cuerpos territoriales que habían heredado del constitucionalismo gaditano una amplia autonomía, sustancialmente reconocida luego en el contexto republicano» (p. 344). Este hecho explicaría que el Estado en su proyecto de fortalecer su poder, circunscribiera el sufragio a los alfabetos en 1896.

La investigación de Chiaramonti está sustentada en un gran trabajo de fuentes y sobre todo en una novedosa perspectiva de análisis constitucional y electoral. Sin embargo, se podría argüir que la autora extiende al caso peruano la tesis de Annino respecto a la experiencia municipal mexicana sin plantear sus diferencias. En ese sentido, da la impresión de que la experiencia gaditana generó el mismo proceso de autonomía local. Así, se podría objetar que no podía ser igual en la medida que en el Perú no triunfó el federalismo; además, genera dudas que entre 1820 y 1860 las municipalidades existieron con la fuerza que le imprime la autora sobre todo si tenemos en cuenta que el rol de los prefectos, subprefectos y gobernadores en la política local no era solo nominal sino parte importante de las alianzas políticas de los caudillos. Eso es evidente 
sobre todo entre 1839 y 1855 cuando las municipalidades fueron suspendidas y reemplazadas por los gobernadores. Así, en las elecciones presidenciales de 1849-1851 es notoria la injerencia de los prefectos; posteriormente, en la revolución de 1854, las actas de los pueblos rebelados señalan la presencia de síndicos procuradores y gobernadores y no de municipios. Por otra parte, y pasando a otro tema, nada parece indicar que la vida parlamentaria fue normal. El rol del parlamento, a diferencia de las cortes de antiguo régimen, es el de gobernar y formar parte del Estado y no ser un cuerpo externo a este. Nada de ello ocurrió entre 1820 y 1840 : el parlamento se reunió doce veces a pesar de que las constituciones de 1823, 1828 y 1834 establecieron su reunión anual. El problema era que de esas reuniones solo siete cumplieron más o menos su rol gobernante y cuatro de ellas se realizaron durante el primer gobierno de Gamarra (1829-1833). Además, entre 1840 y 1845 el parlamento no funcionó y recién entre 1845 y 1860 tuvo una vida más estable. Hasta entonces, por lo general su convocatoria correspondía al caudillo, por ello no extraña que la representación responda a un mandato imperativo. No podían reclamar representar a la nación cuando en realidad representaban a un sector alzado en armas. Como último punto, si seguimos las tesis de Annino ipor qué no se puede hablar de que tras esta experiencia local hay una especie de «liberalismo popular» y no, como menciona Chiaramonti, un regreso a la tradición «pactista»? Con todo y para finalizar esta reseña, habría que resaltar que más que objeciones, este libro sugiere con su novedoso análisis algo más interesante y productivo para la investigación histórica: nuevas preguntas. 